\title{
MODELO DE RISCO E DECISÃO DE CRÉDITO BASEADO EM ESTRUTURA DE CAPITAL COM INFORMAÇÃO ASSIMÉTRICA
}

\author{
Régis Façanha Dantas \\ Caixa Econômica Federal \\ Fortaleza - CE \\ Sérgio Aquino DeSouza* \\ Pós-Graduação em Economia (CAEN) e \\ Departamento de Teoria Econômica (DTE) \\ Universidade Federal do Ceará (UFC) \\ Fortaleza - CE \\ sergiodesouza@caen.ufc.br \\ * Corresponding author / autor para quem as correspondências devem ser encaminhadas \\ Recebido em 04/2007; aceito em 04/2008 após 1 revisão \\ Received April 2007; accepted April 2008 after one revision
}

\begin{abstract}
Resumo
A partir de uma amostra 241 empresas da Indústria Manufatureira brasileira, concluímos que parâmetros que definem a estrutura de capital das empresas são bons sinalizadores para discriminar as empresas quanto ao seu risco de crédito em um ambiente de informação assimétrica. Para chegar a tal resultado, usamos uma equação regressão do tipo Logit, cujas variáveis explicativas são oriundas da análise fatorial e da regressão discriminante através do método stepwise backward. Outro ponto importante é a incorporação de um modelo de decisão de crédito com o uso de programação Linear Inteira como o desenvolvido por Gehrlein \& Wagner (1997).
\end{abstract}

Palavras-chave: análise fatorial; programação linear; risco de crédito.

\begin{abstract}
From a sample of 241 firms in the Brazilian manufacturing sector, we conclude that parameters that define firms' capital structure are good signals of the risk of default on bank loans. In order to derive this result, we use a Logit regression, in which the explanatory variables come from factor analysis and stepwise regression. We also combine this methodology with a model of credit granting that incorporates integer linear programming as developed by Gehrlein \& Wagner (1997).
\end{abstract}

Keywords: factor analysis; linear programming; credit risk. 


\section{Introdução}

Toda decisão de alocação de recursos tem um componente relativo ao risco, seja ele do acionista, relacionado ao retorno do investimento, seja do banco, relacionado ao retorno dos recursos emprestados. A alocação eficiente por parte da empresa é que vai garantir os retornos. No entanto, o custo do capital, seja próprio (acionista) ou de terceiro (financeiro), que dá lastro aos investimentos, é um importante componente dos custos e, assim, dos resultados alcançados.

A estrutura de capital constitui-se, então, num importante sinalizador da situação econômicofinanceira da empresa, dado que se compõe de capital próprio e de terceiros, com custos diferenciados e que dão o lastro para a atividade operacional da empresa geradora do resultado. Assim, deve-se verificar qual a estrutura ótima de capital para a firma e de que forma essa estrutura afeta o seu desempenho ao longo do tempo, uma vez que o sistema financeiro, principalmente o setor bancário, é um dos grandes fomentadores de recursos para o setor empresarial. Dado o caráter de empréstimo, estes recursos/créditos devem retornar sob pena de falência e/ou crise do setor. Portanto, torna-se necessária a avaliação do risco de crédito do tomador.

No Brasil, há uma demanda reprimida por crédito (um hiato de crédito) que, somada às expectativas, pode gerar um crescimento da oferta deste serviço, gerando aumento substancial do endividamento. Para o atendimento destas necessidades de recursos dos diversos agentes econômicos, o mercado financeiro através dos diversos intermediários, bancos principalmente, e mercados de capitais, fomentam a economia compatibilizando os recursos para cada necessidade, no que se chama de mercado completo, ou seja, aquele em que existe um ativo específico para cada estado da natureza, estando o crédito bancário como o principal instrumento para saciar esta necessidade de recursos.

Um problema preponderante que freia a expansão do crédito refere-se ao ambiente de informação assimétrica no qual convive o setor bancário. Os clientes detêm informações sobre seu tipo, bom (boa situação financeira) ou ruim (má situação financeira), que consiste em uma informação privada e privilegiada. Os bancos apenas sabem que tais tipos existem e buscam uma sinalização por partes dos agentes (clientes) para decidir sobre o crédito, mas a falta de transparência nas informações contábeis, econômicas e financeiras disponibilizadas pela empresa, principalmente aquelas de capital fechado, eleva o risco de crédito do setor.

A problemática pode ser resumida nas questões abaixo:

1. Como obter a melhor sinalização para o tipo do cliente-empresa dado sua estrutura de capital em um ambiente de informação assimétrica?

2. Qual melhor modelo para mitigar e classificar o risco de crédito com base nas técnicas estatísticas?

3. Qual técnica a ser usada para auxiliar a tomada de decisão na liberação de crédito para determinado cliente, dado o seu nível de risco?

Uma solução então seria incorporar modelos de risco que captassem melhor a sinalização do tipo do cliente (Bom e Ruim) por indicadores de conhecimento geral do mercado, transparentes e quantificáveis.

Infere-se aqui que a introdução de um modelo de classificação do risco de crédito e outro para decisão de crédito no processo de análise poderão diminuir substancialmente a parte dos 
juros que se relaciona com o risco de crédito, amenizando os problemas causados pela informação assimétrica. No entanto, quais sinalizadores devem ser utilizados, uma vez que o agente tem um incentivo para emitir informação distorcida em benefício próprio dada a assimetria de informação.

A resposta vem então da importância da Estrutura de Capital para o equilíbrio financeiro da empresa. Portanto, a hipótese consiste em buscar a melhor sinalização dentro da estrutura de capital que revele a real situação econômico-financeira do tomador, cuja sinalização ou o conjunto de sinais (variáveis) deverá explicar o nível de risco dentro de um modelo apropriado.

Os estudos sobre análise e predição de falência iniciaram-se em 1968 com Edwards Altman na publicação do artigo "Financial ratios, discriminant analysis and the prediction of corporate bankruptcy". A partir daí, uma série de estudos e modelos foram propostos e utilizados no mercado. No Brasil, os principais modelos, que usam critérios estatísticos como análise discriminante, entre outros, são os modelos de Altman \& Baidya (1979), Matias (1978), Elizabetsky (1976), Silva (1997) e recentemente o de Scarpel \& Milioni (2001). Neste último, os autores inovam incorporando a programação linear inteira para propor um modelo de decisão de crédito.

Apesar do uso de instrumentos estatísticos para escolha e redução de indicadores nos modelos acima citados, não observamos citações sobre o ambiente de informação assimétrica que é comum nestes agentes (empresas), como também a falta de se inserir os custos dos diferentes tipos de erros nas previsões (tipo II - empresas más classificadas como boas e tipo I - empresas boas classificadas como más), conforme observados por Scarpel \& Milioni (2001). Neste trabalho, incorporamos no modelo soluções para estes problemas observados.

\section{Referencial teórico}

\subsection{Teorias da Estrutura de Capital}

A estrutura de capital das empresas refere-se às fontes de recursos utilizadas, ou ainda, a relação entre as dívidas de curto, médio e de longo prazos (PC + ELP) e capital próprio (PL). $\mathrm{O}$ esforço das firmas em gerar resultado passa necessariamente por sua estrutura de capital; as fontes de recursos definirão o grau de flexibilidade do capital na busca da eficiência econômico-financeira.

Os estudos sobre Estrutura de Capital começaram com os teoremas MM - Modigliani \& Miller (1958), tais estudos referem-se principalmente a relação Dívidas - Benefícios de impostos no tratamento da estrutura de capital. Segundo estes teoremas, uma empresa não pode alterar seu valor simplesmente alterando as proporções dos capitais próprio e de terceiros de sua estrutura de capital.

Contrariando os teoremas MM, modelos baseados em assimetria informacional observam os problemas oriundos de mercados onde os agentes econômicos são heterogêneos com respeito ao conjunto de informações que possuem. Um agente dispõe de informação privilegiada e, o outro, chamado de principal, sabendo de sua deficiência informacional, tenta captar a melhor informação disponível. 
O determinante da estrutura de capital nestes modelos é dado pelo objetivo de comunicar informação privada para os mercados de capitais ou diminuir os efeitos da seleção adversa. Nessas teorias, os gerentes (insiders) detêm informações sobre as características da empresa (fluxos de caixa, retornos de investimento, etc.) que os investidores (outsiders) não possuem. Estes modelos objetivam diminuir ineficiências causadas pela assimetria informacional nas decisões de investimento das empresas. Essas ineficiências causam investimentos não ótimos. Como a empresa detém mais e melhores informações que o mercado, este tende a sub avaliar a empresa, que acaba por optar por recursos internos.

Nos modelos com sinalização como proporção da dívida, o investimento é fixo e a escolha da estrutura de capital sinaliza as informações dos gerentes (insiders) para os investidores (outsiders). As firmas de melhor qualidade sinalizam para os investidores sua condição ao se endividarem mais, pois, como o custo marginal esperado de falência é maior para as firmas de baixa qualidade, os gerentes das piores firmas não imitarão os gerentes das melhores. A implicação para a estrutura é que se espera uma relação positiva entre a rentabilidade (e consequentemente o valor) da firma e a razão dívida / ações.

Famá \& William (2000) resumiram com bastante eficiência a evolução histórica das teorias sobre estrutura de capital. Os autores dividem o estudo em três fases: a primeira, indo até a década de 1950, em que a noção intuitiva de risco, segundo os autores, não era acompanhada de um instrumental analítico adequado para tratá-lo. A segunda fase, iniciada com estudos de Markowitz (1952), Modigliani \& Miller (1958) e outros trabalhos que os sucederam como por exemplo Jensen \& Meckling (1976), poderia ser chamada da fase da incerteza dos fatos, pois a incerteza passou a ser considerada assim como novas teorias (por exemplo, a Teoria da Agência e Política de Dividendos, introduzida por Ross, 1977).

\subsubsection{Assimetria Informacional e Estrutura de Capital}

Dado um ambiente de informação assimétrica, consequentemente emerge uma situação de incerteza dos fatos, dos eventos relativos às empresas e indivíduos.

As informações contidas nos demonstrativos econômico-financeiros são fontes inesgotáveis de assimetria informacional. As empresas, dependendo do objetivo, podem "trabalhar" os dados dos balanços de tal modo que as informações ali extraídas não espelhem a realidade da empresa, mas sim a situação que o empresário gostaria de passar como informação, como sinal. Por exemplo, para diminuir o pagamento de impostos, a empresa pode fazer operações e/ou escriturações em que as despesas sejam aumentadas para diminuir o lucro final. Não necessariamente trata-se de ilegalidade, mas aproveita-se a legislação em vigor para isso. É o chamado "planejamento tributário". No entanto, isto provoca muitas vezes informações erradas sobre os indicadores econômico-financeiros da empresa. Outras tantas informações não são captadas, como qualidade dos investimentos, custos de oportunidades, etc.

A estrutura de capital, traduzida na origem de recursos da empresa, passivo, é um conjunto de informações que, teoricamente, é menos suscetível à manipulação ou ao planejamento tributário, uma vez que o nível de endividamento da empresa é de fácil comprovação e seus dados estão disponibilizados no SISBACEN (Sistema de Informações do Banco Central). Já o capital próprio, também tem seu montante traduzido em contrato, estatuto e ações acompanhadas por diversos órgãos. Deste modo, num ambiente de assimetria informacional, a busca de bons sinalizadores advindos da estrutura de capital poderá amenizar as conseqüências da desinformação. 
Com informação assimétrica, as firmas e governos com projetos de baixo risco deixarão o mercado, pois terão de enfrentar os custos mais elevados de crédito, já que o credor não tem condições de distingui-los das suas contrapartes mais arriscadas. Somente os tomadores de maior risco permanecerão. Os tomadores de empréstimos que têm possibilidade de escolher projetos passarão às alternativas mais arriscadas a fim de aumentar a chance de serem capazes de arcar com o serviço da dívida mais elevado. Se o credor detém esta informação (mas não sabe a que categoria pertence cada tomador de crédito ou projeto específico), um aumento no custo de oportunidade dos fundos pode, então, causar um colapso repentino dos empréstimos ao mercado.

Assume-se aqui, conforme a seleção adversa, que o principal não pode observar o tipo do agente: alto ou baixo risco, apenas sabe que há os dois tipos de clientes com uma determinada probabilidade para cada um.

Uma das opções para resolver esta assimetria informacional (o agente sabe seu tipo-projeto mas o banco não), é o banco reconhecer que o tomador com maior risco irá preferir não usar seu capital próprio, e sim de terceiros, até porque, maiores riscos estão associados a maiores retornos, o que deve ser suficiente para honrar taxas de juros maiores conforme o risco. Assim, o capital serve como um sinal para o cliente com qualidade. A idéia é para o banco designar caminhos para que a tomada de empréstimos seja incentive compatible ou na linguagem da Teoria dos Jogos, um contrato second-best. Em outras palavras, nenhum tomador deverá ter incentivos para desviar do contrato que o banco entende ser o melhor para ele. Com incentive compatibility deverá ser obtido um equilíbrio de nash. O problema é definir contratos com estas características.

Uma segunda opção, adotada neste artigo, consiste em captar o tipo do agente. O modelo de análise de risco busca a utilização da sinalização " $\theta$ " (que pode ser função de vários indicadores) captada na empresa para avaliar e quantificar o risco deste determinado clienteempresa e oferecer-lhe um contrato que lhe seja compatível, ou seja, que o agente tenha revelado seu tipo $\theta$ através da situação econômico-financeira representada pelos demonstrativos contábeis (estrutura de capital principalmente) e em outras informações relevantes sem incorrer num alto custo para o mercado. A sinalização captada pelo modelo e a conseqüente classificação de risco fará com que o banco tenha melhores informações sobre o cliente, podendo, inclusive, exigir juros compatíveis (menores) pela diminuição da informação assimétrica e a conseqüente diminuição da probabilidade de inadimplência. Desta forma, será possível definir um contrato first-best, ou seja, fazer uma discriminação de preços de primeiro grau.

\subsection{Modelo de Risco e Decisão de Crédito}

Avaliar o risco de crédito é, portanto, avaliar a probabilidade do agente (tomador de crédito) não honrar suas obrigações nos respectivos vencimentos. Os sistemas de concessão de crédito, escoragem ou julgamental, estão baseados na premissa de que o futuro, pelo menos a curto prazo, será muito parecido com o passado recente. Não há como saber com antecedência se uma empresa pagará ou não. Assim, na modelagem procura-se fazer um comparativo entre as características dos clientes (no caso empresas) que tiveram seus créditos inadimplidos e as características dos clientes cujo crédito foi cumprido. Em outras palavras, procura-se traçar o perfil dos bons e maus clientes. 
Após quantificado pelo modelo o risco inerente a cada tomador e grupo de tomadores, resta à Política de Crédito a decisão da concessão ou não a cada grupo por grau (classificação) de risco. Esta decisão é definida pelo ponto de corte.

O ponto de corte é o ponto de decisão que separa aqueles que irão ou não receber crédito. $\mathrm{O}$ Ponto de Corte $(V c)$ será o ponto na escala de scores no qual todos os proponentes serão aprovados se estiverem igual ou acima dele e serão reprovados aqueles que estiverem abaixo de $V c$.

$$
\text { P(i) = Função Discriminante, Probit ou Logit (score do cliente i). }
$$

Então:

$$
\begin{aligned}
& \mathrm{P}(\mathrm{i}) \geq \mathrm{Vc} \longrightarrow \text { Aprovado } \\
& \mathrm{P}(\mathrm{i})<\mathrm{Vc} \longrightarrow \text { Reprovado }
\end{aligned}
$$

\section{Metodologia}

Para o desenvolvimento do modelo, utilizamos o método estatístico multivariado com variável dependente discreta, a regressão Logit. No entanto, em face dos problemas comuns de multicolinearidade dos dados econômico-financeiros que provocaria uma relevante diminuição na quantidade de variáveis incorporadas na regressão, utilizamos a Análise Fatorial de Componentes Principais.

O uso da Análise Fatorial no tratamento e configuração das variáveis explicativas qualifica ainda mais as variáveis independentes usadas, colocando-as em grupos de explicação que captam melhor os efeitos dos diversos indicadores econômico-financeiros. Em outras palavras, serão utilizados fatores para compor as variáveis explicativas do modelo. Como veremos adiante, estes fatores são frutos de agrupamentos de indicadores.

Outro ponto importante é a incorporação de um modelo de decisão de crédito com o uso de programação Linear Inteira. $\mathrm{O}$ uso deste modelo incorpora cenários relativos a diferentes taxas de juros, qualificando o ponte de corte (limites de aceitação) para tomada de decisão sobre a decisão de crédito.

Neste artigo, o modelo de risco tenta avaliar a capacidade de uma ou mais variáveis usadas como sinalizadores de possível insolvência em discriminar de forma eficiente as empresas entre boas e más, entendendo-se como boa a empresa que possui condições econômicofinanceiras de honrar seus compromissos. Para cumprir estes objetivos, utilizaram-se critérios estatísticos, matemáticos e econométricos na construção do modelo sobre as variáveis escolhidas. Por motivos expositivos, apresentamos o fluxograma das técnicas usadas no modelo: 
Fluxograma das Técnicas Usadas no Modelo

$1^{\circ}$ Passo: Escolha dos Indicadores (Econômico-Financeiros) Discriminantes. Objetivo: Escolha das variáveis explicativas compatíveis com o modelo.

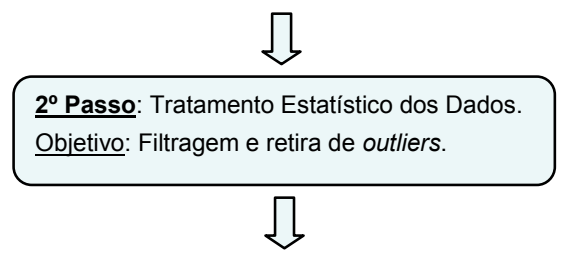

3० Passo: Análise Fatorial sobre os indicadores discriminantes.

Objetivo: Corrigir problemas de multicolinearidade dos dados e encontrar grupos (fatores) de explicação das variáveis.

\section{ת}

4 Passo: Regressões para Análise Discriminante com a utilização do método Stepwise Backward sobre os fatores e variáveis provenientes da Análise Fatorial.

Objetivo: Identificar variáveis e fatores (da Análise Fatorial) mais explicativos para escolha das variáveis independentes.

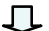

50 Passo: Modelo de Risco de Crédito com uso da Regressão Logit.

Obietivo: Discriminar empresas em solventes e Insolventes a partir das variáveis explicativas selecionadas no $4^{\circ}$ passo

\section{П}

6 Passo: Modelo de Decisão de crédito com uso da Programação Linear Inteira.

Objetivo: Definir o Ponto de Corte para tomada de decisão de conceder ou não credito para as empresas que estão abaixo e acima do corte.

\subsection{Fonte dos Dados e Filtragem}

A fonte principal dos dados vem da ECONOMÁTICA (data@ software investment analysis), trata-se de um rico banco de dados colhidos na Bolsa de Valores com universo de empresas nacionais e estrangeiras com ação na Bolsa.

A população inicial era composta de 241 empresas da Indústria Manufatureira. Deste total foram retiradas 102 empresas as quais não dispunham de ativo nos anos utilizados, restando 139 empresas. Destas empresas, mais um filtro foi necessário, retiramos todas as empresas que tinham Patrimônio Líquido (PL) negativo, isto foi feito para eliminar um viés teórico, pois empresas com $\mathrm{PL}<0$ estão totalmente comprometidas financeiramente, uma vez que tal situação evidencia que os sócios não são mais proprietários da empresa e sim, terceiros. Outro motivo é exclusão das variáveis com valores extremos. As empresas com $\mathrm{PL}<0$ ficavam com seus indicadores extremamente elevados, causando distorção na análise. Assim, ficamos com 114 empresas na amostra final.

Das 114 empresas, 63 são caracterizadas como "boas" e 51 como "más", seguindo o critério de inadimplência acima de 30 dias no mercado financeiro observada através do cadastro do SISBACEN (Sistema do Banco Central) em 2005. 
A estabilidade do modelo ou performance é testada ao utilizarmos dados de adimplência e inadimplência de outubro e dezembro de 2004, ou seja, empresas fora da amostra da estimação do modelo. Nesta amostra de 98 empresas, foram classificadas pelo mesmo critério já exposto, 75 como "boas" e 23 "más". Também aqui retiramos as empresas com $\mathrm{PL}<0$. As variáveis necessárias para testar $\mathrm{o}$ modelo foram obtidas a partir dos demonstrativos contábeis anuais das empresas no período de 2003 e 2004.

\subsection{Indicadores (sinalizadores) Econômico-Financeiros}

Segundo Gitman (1997), por conveniência, os índices financeiros podem ser subdivididos em quatro grupos: índices de liquidez, de atividade, de endividamento e de lucratividade. Focando na hipótese do artigo de que a estrutura de capital poderá fornecer bons indicadores da saúde financeira da empresa e assim, diminuir os problemas de seleção adversa, buscamos mais indicadores de Estrutura de Capital e, consequentemente, de endividamento para tentarmos captar a melhor sinalização do agente empresarial quanto ao seu risco de crédito. No entanto, com o objetivo de usarmos em nosso modelo toda informação disponível relevante da empresa e assim, evitarmos erros de especificação, buscamos também selecionar os indicadores mais representativos de cada um dos grupos acima citados.

A escolha dos indicadores levou em consideração prioritariamente o ambiente de informação assimétrica, escolhendo os indicadores que, teoricamente, são menos susceptíveis a manipulação e que menos sofrem a administração tributária, ou seja, que são menos influenciados por contas (do ativo, passivo e demonstração de resultados) que usualmente são "trabalhadas" para pagamento de menos impostos e outros objetivos. Neste caso, podemos classificar em ordem de menor influência: Estrutura, Liquidez e Lucratividade. A Estrutura de Capital e Liquidez têm como fonte principal o Balanço Patrimonial e, como se trata de dados de estoque, a comprovação dos valores absolutos são mais fáceis de serem verificados. Já os índices de lucratividade com base do Demonstrativo de Resultado, que tem dados de fluxo, são operacionalmente mais suscetíveis a manipulações.

$\mathrm{Na}$ tabela a seguir temos os indicadores inicialmente escolhidos e colhidos em nossa amostra. Tais indicadores referem-se ao ano de 2004. Na respectiva tabela temos os indicadores LB, AP, ALP, AFC, PFC, CTF, DivTliq, CT/PL, LG, LC, ML, GiroAT, RentAT, RentPL, AlaFin, FxBT, Comp e CT.

Tabela 1 - Indicadores Discriminantes.

\begin{tabular}{cl} 
Indicador & \multicolumn{1}{c}{ Significado } \\
\hline \hline LB & Lucro Bruto \\
AP & Participação do Imobilizado no Ativo \\
ELP & Participação do Exigível a LP no Passivo Total \\
AFC & Ativo Financeiro Circulante/AT \\
PFC & Passivo Financeiro Circulante/AT \\
CTF & Capital Total Financeiro Circulante/AT \\
DivTTLiq & Dívida Total Líquida sobre o PT \\
CT/PL & Capital de Terceiros sobre o PL
\end{tabular}




$\begin{array}{cl}\text { LG } & \text { Liquidez geral } \\ \text { LC } & \text { Liquidez Corrente } \\ \text { ML } & \text { Margem Líquida } \\ \text { GiroAt } & \text { Giro do Ativo } \\ \text { RentAt } & \text { Rentabilidade do Ativo } \\ \text { RentPL } & \text { Rentabilidade do PL } \\ \text { AlaFin } & \text { Alavancagem Financeira } \\ \text { Flx Bruto } & \text { Participação do Fluxo Bruto no Ativo Total } \\ \text { Comp } & \text { Composição da Dívida de Terceiros sobre o PT } \\ \text { CT } & \text { Capital de Terceiros sobre o Ativo Total }\end{array}$

\subsection{Análise Fatorial de Componentes Principais}

Assim como a análise de componentes principais, a análise fatorial é uma técnica de análise multivariada. Segundo Haddad (1989), a análise fatorial é um instrumento mais poderoso e genérico que a de componentes principais, por que permite não só a rotação dos eixos (fatores) que sintetizam as informações contidas na matriz de dados, cuja finalidade é facilitar a interpretação analítica dos mesmos, como também o estabelecimento de eixos nãoortogonais que representam o mútuo relacionamento entre fatores que são interdependentes, mais de acordo com as associações observadas na realidade.

Em suma, a utilização da análise fatorial de componentes principais é realizada com o propósito de localizar de forma objetiva categorias independentes de variáveis ("índices"), de forma a evitar a redundância informativa e os problemas que a existência de multicolinearidade pode provocar no resultado da análise.

A rotação dos fatores é feita com a finalidade de melhor definir as relações entre as variáveis e os fatores. A rotação pode ser ortogonal ou oblíqua, ou seja, os eixos (fatores) podem ser rodados de maneira a preservar a independência entre os fatores ou não. Na rotação ortogonal, os métodos comumente usados são o quartimax e o varimax. Neste trabalho usamos o varimax, pois permite definir mais claramente quais variáveis estão associadas com um dado fator e quais não estão.

A partir da Tabela 1, podemos selecionar os indicadores para uma análise combinada (liquidez, rentabilidade e estrutura- endividamento) dada a relevância de cada um desses índices na explicação da situação financeira das empresas. Um ponto relevante, como já citado, é o problema de multicolinearidade dos indicadores quando inseridos numa regressão múltipla. Este fato foi o principal motivador para utilizarmos a Análise fatorial dos Componentes Principais.

\subsection{Metodologia Econométrica - Modelo Logit}

Encontrar o melhor modelo para estimação econométrica com o objetivo de classificação de risco requer não apenas o conhecimento teórico a priori das relações possíveis entre as variáveis como também os objetivos a serem alcançados e a verificação da performance do modelo. 
Neste trabalho faremos uso do modelo Logit devido a característica binária da variável dependente, como também pelo fato da análise discriminante ser meramente uma técnica de classificação, enquanto o modelo Logit analisa uma relação causal. Como não estamos interessados apenas numa classificação dicotômica das empresas, mas também na estimação dos coeficientes das variáveis independentes e, consequentemente, na determinação da probabilidade de ocorrência de insolvência, o modelo Logit é o mais apropriado ao nosso estudo. A performance será avaliada pelo nível de acerto na classificação da empresas.

Seja $\boldsymbol{X}_{i}$, o vetor $1 x K$ de variáveis explicativas (neste caso, fatores) da empresa i e $\boldsymbol{\beta}, \mathrm{o}$ vetor $K x 1$ de parâmetros. $O$ vetor $\boldsymbol{\beta}$ reflete o impacto da variação das variáveis explicativas na probabilidade de adimplência. A idéia então é utilizar uma função que transforme $\boldsymbol{X} \boldsymbol{\beta}$ num número entre 0 e 1 , e isto é possível, utilizando-se de uma função de distribuição acumulada $\mathrm{F}$ para a probabilidade de ser adimplente $\left(Y_{i}=1\right)$

$$
\operatorname{prob}\left(Y_{i}=1 / X_{i}\right)=F\left(X_{i} \beta\right)
$$

Assim, temos a garantia que:

$$
\begin{aligned}
& \lim _{X \beta \rightarrow+\infty} \operatorname{prob}(Y=1)=1 \\
& \lim _{X \beta \rightarrow-\infty} \operatorname{prob}(Y=1)=0
\end{aligned}
$$

Escolhendo a distribuição logística como a função de distribuição na equação 1, estaremos definindo o modelo Logit:

$$
\operatorname{prob}\left(Y_{i}=1 / X_{i}\right)=\Lambda\left(X_{i} \beta\right)=\frac{\exp \left(X_{i} \beta\right)}{1+\exp \left(X_{i} \beta\right)}
$$

Observe que $\boldsymbol{X} \boldsymbol{\beta}$ varia de $-\infty$ a $+\infty$, a $\operatorname{prob}\left(Y_{i}=1 / X_{i}\right)$ varia entre 0 e 1 e não se relaciona linearmente com $\boldsymbol{X} \boldsymbol{\beta}$. Se $\Lambda(X \beta)$ é a probabilidade de não ser inadimplente, então $1-\Lambda(X \beta)$ é a probabilidade de ser inadimplente. Logo,

$$
\frac{\Lambda(X \beta)}{1-\Lambda(X \beta)}=\frac{1+\exp X \beta}{1+\exp (-(X \beta))}=\exp X \beta
$$

é simplesmente a razão de probabilidade em favor de ser adimplente. Esta relação é chamada de odds de um evento e é definida como o quociente entre a probabilidade que o evento ocorra e seu complementar.

Observa-se então que $\boldsymbol{\beta}_{k}$ dá a variação percentual na chance de ser adimplente. Dado o fator multiplicativo devido aos coeficientes estarem em expoente, um coeficiente menor que 1 diminui a chance de ser adimplente e maior que 1 aumenta a chance.

Para verificar os efeitos marginais dos parâmetros na probabilidade, devemos notar que a derivada da probabilidade de adimplência em relação i-ésimo componente do vetor de variáveis explicativas $\boldsymbol{X}_{i}$ depende do nível de todas as variáveis que compõe o vetor $\boldsymbol{X}$.

$$
\frac{\partial P\left(Y_{i}=1 / X_{i}\right)}{\partial X_{i}}=\rho(1-\rho) \beta_{i}
$$


Onde

$$
\rho=\frac{\exp \left(X_{i} \beta\right)}{1+\exp \left(X_{i} \beta\right)}
$$

Neste artigo utiliza-se o critério da chance proporcional para calcular o termo $\rho$ que entra no cálculo do efeito marginal. Para diferenciar da equação 5 , definiremos a chance proporcional por $\eta$. O cálculo de $\eta$ é obtido a partir da seguinte equação:

$$
\eta=\vartheta^{2}+(1-\vartheta)^{2}
$$

Sendo:

$$
\begin{aligned}
\eta & =\text { chance proporcional } \\
\vartheta & =\text { proporção de elementos do grupo } y=1 \\
(1-\vartheta) & =\text { proporção de elementos do grupo } y=0
\end{aligned}
$$

\subsection{Programação Linear Inteira}

O uso da Programação Linear Inteira deve-se a necessidade de se retirar a subjetividade no critério de escolha do Ponto de Corte (Vc), bem como evitar o uso de critérios pouco robustos, como por exemplo, o uso da média simples ou média ponderada dos scores ou uso de $50 \%$ ou 0,5 como score. Além disso, o uso da PLI abre a possibilidade do uso de cenários de mercado através da taxa de juros e custos incidentes.

Programação Linear Inteira (PLI) é um problema de Programação Linear em que todas ou algumas variáveis são discretas (têm que assumir valores inteiros). Existe um caso especial de variáveis inteiras: as variáveis binárias que apenas podem tomar os valores 0 (zero) ou 1 (um).

Utilizaremos aqui o modelo de Programação Linear Inteira desenvolvido por Gehrlein \& Wagner (1997) e modificado por Scarpel \& Milioni (2002) e neste trabalho, incorporamos na análise o ponto de equilíbrio e a relação de compensação entre o custo de um cliente ruim e o retorno de um cliente bom. O objetivo é conceber um modelo que forneça suporte a decisões de concessão de crédito em função da estimativa da probabilidade de solvência de empresas, de forma a minimizar a soma dos custos de oportunidade e inadimplência. Em outras palavras, utiliza-se a PLI para a definição do ponto de equilíbrio.

A Programação Linear Inteira (PLI) permite o subsídio às decisões de concessão de crédito às empresas em função da política de juros estabelecida pelo concedente de crédito, uma vez que o modelo tem uma função objetivo que leva em consideração o custo de inadimplência e o custo de oportunidade dos empréstimos, minimizando a soma desses dois.

O modelo utilizado por Scarpel \& Milioni (2002) usa a função Logit P(i). A exemplo deste trabalho prosseguimos ao uso do Logit. O problema passa a ser então:

$$
\operatorname{Min}\left[\operatorname{Cin} \sum_{i \in d} l_{i}+\operatorname{Cop} \sum_{i \in p} l_{i}\right]
$$

restrições :

$$
\begin{aligned}
& P(i)-M . l_{i} \leq V c-\varepsilon, \forall i \in d \\
& P(i)+M . l_{i} \geq V c+\varepsilon, \forall i \in p
\end{aligned}
$$


Seja $d$ o conjunto de clientes que não pagou o empréstimo e $p$ o conjunto de clientes que pagou o empréstimo; seja $\operatorname{Cin}$ o custo associado à classificação de um cliente que não pagaria o empréstimo como um cliente que pagaria e, analogamente, Cop o custo associado à classificação de um cliente que pagaria o empréstimo como um cliente que não pagaria.

$\mathrm{O}$ empréstimo será fornecido quando $P(i)>V c$ e negado quando $P(i) \leq V c$. Como $P(i)$ é uma probabilidade, $V c$ estará forçosamente contido no intervalo [0,1], como afirma Scarpel \& Milioni (2002).

Na Função Objetivo:

(a) $\operatorname{Cin} \sum_{i \in d} l_{i}$ é a parcela do custo de inadimplência, assim, só teremos custo de inadimplência quando classificarmos erroneamente $\left(l_{i}=1\right)$ uma empresa pertencente ao grupo de inadimplentes $(i \in d)$, ou seja, caso seja concedido crédito a uma empresas classificada como má.

(b) $\operatorname{Cop} \sum_{i \in p} l_{i}$ é a parcela do custo de oportunidade, assim, só teremos custo de oportunidade quando classificarmos erroneamente $\left(l_{i}=1\right)$ uma empresa pertencente ao grupo de adimplentes $(i \in p)$, ou seja, caso seja negado crédito a um cliente bom.

(a) + (b) então á soma dos custos incidentes originados por classificação errada. O objetivo é minimizar este custo. Os componentes e cálculos dos custos Cin e Cop estão na seção a seguir.

As restrições 8 e 9 são definidas a partir da regra de decisão:

$$
\begin{array}{ll}
\text { Aprovada: } & P(i)>V_{c} \\
\text { Reprovada: } & P(i) \leq V_{c}
\end{array}
$$

O objetivo então é encontrar o ponto (valor) de corte $(\mathrm{Vc})$ que minimize os custo associados com os erros de classificação na função objetivo. O resultado desta minimização consiste na solução ótima.

A introdução de $\mathrm{M}$ (número positivo e grande) e $\varepsilon$ (positivo e pequeno em relação a $\mathrm{M}$ ) como variáveis complementares no algoritmo da programação linear inteira tem como objetivo assegurar a solução ótima através de um algoritmo que diminua o tempo (carga) computacional, assegurando a validade de cada restrição.

\subsubsection{Quantificação e Cenários dos Custos Associados utilizados no Modelo de Decisão (Ponto de Corte)}

Para definição do Ponto de Corte, $V c$, é necessário que o custo do dinheiro seja incorporado nesta decisão. Em outras palavras, a taxa de juros deve ser inserida na análise para que se possa medir qual o custo de se incorrer nos erros Tipo I e Tipo II. O erro Tipo II é a possibilidade de classificarmos como "boa" uma empresa "má". Já o erro Tipo I é a possibilidade de classificarmos como "má" uma empresa "boa". Isto se refere aos diferentes custos de alocar um elemento do grupo 2 no grupo 1, ou seja, o erro do tipo I e tipo II.

Os erros acima citados incorrem em custo adicionais ao serem realizados. Estes custos podem ser definidos como o custo de oportunidade e o custo de inadimplência. 
O Custo de Oportunidade (Cop) refere-se ao custo de deixar de ganhar, da perda de um cliente bom e a conseqüente perda da margem de contribuição que o mesmo adicionaria ao resultado. O Cop nada mais é que o Erro Tipo I.

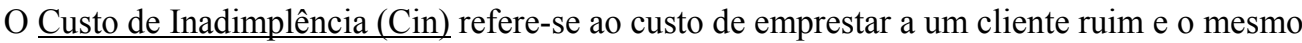
inadimplir, deixar de pagar os valores acordados em contrato. O Cin é o Erro Tipo II.

Com poucas alterações nas variáveis usadas, utilizamos a metodologia de Scarpel \& Milioni (2002) para quantificação dos custos de oportunidade e de inadimplência. Os autores exemplificaram os custos através de um empréstimo de 1.000 unidades monetárias (u.m) por um período de 12 meses e supondo ainda que em caso de inadimplência esta somente ocorra depois de ter sido pago 30\% do principal emprestado (VP).

$\mathrm{O}$ valor pago mensalmente pelo empréstimo, juros, prestação e amortização pode ser calculado pela Tabela Price a partir da fórmula:

$$
R=\operatorname{prestação}=V P \cdot\left(\frac{t \cdot(1+t)^{12}}{(1+t)^{12}-1}\right)
$$

Onde $t$ é a taxa de juros cobrada pelo banco e o fator entre parênteses é o Fator de Recuperação de Capital (FRC) de uma série uniforme de pagamento. Deste modo, o Custo de Oportunidade (Cop) é obtido como segue:

$$
\text { Cop }=(12 * \text { prestação })-100
$$

O Custo de Inadimplência (Cin) é a perda de 70\% do capital, ou:

$$
\text { Cin }=0,70 * V P
$$

A partir daí varia-se a taxa de juros, deixando inalterados os outros parâmetros do cálculo, para efeitos de comparação.

Outro cálculo adicional importante é o ponto de equilíbrio da operação ou da carteira, ou seja, o nível de inadimplência aceitável e limítrofe definido por K. Este valor representa o nível de inadimplência máximo para que não haja retorno negativo dos empréstimos. No ponto máximo $\mathrm{K}$, o retorno é zero.

A fórmula parte do montante de clientes bons que devem ser inseridos na carteira para fazer compensar um cliente mal. Ou seja, caso o banco coloque em sua carteira de empréstimo um cliente ruim e este fique inadimplente, quantos clientes bons (que paguem seus empréstimos) serão necessários para que, com a receita gerada, possa compensar a perda gerada pelo cliente ruim. A esta quantidade chamaremos de $\varphi$.

$$
\varphi=\frac{\text { CustodeInadimplência }}{\text { CustodeOportunidade }}=\frac{\text { Cin }}{\text { Cop }}
$$

O ponto de Equilíbrio, definido aqui por $K$ é igual a:

$$
\mathrm{K}=\frac{1}{1+\vartheta}
$$

Supondo um Valor Principal de R $\$ 1.000,00$ no prazo de 12 meses, vamos verificar como se comportam o $K$-ponto de equilíbrio, $\varphi$ - bons por mal. Trata-se de uma simulação que fica próximo da realidade, o valor monetário em termos absolutos é irrelevante. Quanto à 
inadimplência, um cliente pode deixar de pagar da $1^{\circ}$ ou a partir de qualquer prestação, estamos aqui supondo que ele deixará de pagar a partir da $3^{\circ}$ parcela, configurando-se numa média de determinada carteira. A suposição acima é devida para quantificarmos os custos envolvidos. Embora possamos ter valores de equilíbrios diferentes devido a mudanças dos valores absolutos de empréstimos e prazos de inadimplência, não irão mudar os resultados alcançados. Os resultados, utilizando-se as equações 2, 3, 4 e 5 estão na tabela a seguir:

Tabela 2 - Relação da Taxa de Juros com o nível de inadimplência aceitável $K$ e com o equilíbrio financeiro entre o ganho por cliente "bom" e a perda por uma empresa "má" definido por $\varphi$.

\begin{tabular}{rlrrc} 
Juros(am) & Cin & Cop & $\boldsymbol{\varphi}$ & $\boldsymbol{K}$ \\
\hline \hline 0,01 & 700,00 & 66,19 & 10,58 & 0,09 \\
0,02 & 700,00 & 134,72 & 5,20 & 0,16 \\
0,03 & 700,00 & 205,55 & 3,41 & 0,23 \\
0,04 & 700,00 & 278,63 & 2,51 & 0,28 \\
0,05 & 700,00 & 353,90 & 1,98 & 0,34 \\
0,06 & 700,00 & 431,32 & 1,62 & 0,38 \\
0,07 & 700,00 & 510,82 & 1,37 & 0,42 \\
0,08 & 700,00 & 592,34 & 1,18 & 0,46 \\
0,09 & 700,00 & 675,81 & 1,04 & 0,49 \\
\hline 0,09285 & 700,00 & 700,00 & 1,00 & 0,5 \\
\hline 0,10 & 700,00 & 761,16 & 0,92 & 0,52 \\
0,11 & 700,00 & 848,33 & 0,83 & 0,55 \\
0,12 & 700,00 & 937,24 & 0,75 & 0,57
\end{tabular}

Fonte: Resultados das equações (10) a (14).

Observe na Tabela 2, que o aumento na Taxa de Juros praticada aumenta o nível de inadimplência aceitável, ou seja, a aceitação ao Erro Tipo II. Quando a Taxa de Juros é 1\%, o equilíbrio $\mathrm{K}=9 \%$, ou seja, o limite de inadimplência aceitável é $9 \%$, significando que acima disso, o banco terá prejuízos. Observe pela Tabela 2 que o custo de inadimplência é maior que o custo de oportunidade (Cin > Cop).

O equilíbrio é diretamente proporcional à taxa de Juros. Elevações na taxa de juros elevam o nível de inadimplência aceitável. Isto é uma fonte inesgotável de lucratividade dos bancos, taxas de juros elevadas fazem suportar índices de inadimplência elevadas sem prejuízos para os bancos. A taxa de juros de $9,29 \%$ é a taxa a qual a partir daí, ceteris paribus as outras variáveis, o custo de inadimplência é menor que o custo de oportunidade (Cin $<$ Cop), assim, o Erro Tipo I tem o custo maior que o Erro Tipo II, fazendo com que perder um cliente bom custe mais para os bancos que aceitar um cliente ruim, este é um dos motivos principais das financeiras levarem agentes de crédito às praças públicas a procura de cliente sem critérios de escolha.

Com o auxílio da Tabela 2, inserimos agora no contexto três cenários:

$1^{\circ}$ Cenário: Cin $>$ Cop. Neste cenário, a baixa taxa de juros faz com que o custo de inadimplência seja maior que o custo de oportunidade, fazendo com que o emprestador de 
recursos tenha cautela na escolha dos clientes, buscando minimizar o erro Tipo II. No nosso problema, isto acontece quando a taxa é menor que $9,28 \%$

$2^{\circ}$ Cenário: Cin $<$ Cop. Neste cenário, a alta taxa de juros faz com que o custo de inadimplência seja menor que o custo de oportunidade, fazendo com que o emprestador de recursos tenha como ponto de equilíbrio um valor elevado, com uma taxa de inadimplência aceitável acima de 50\%. Deste modo, busca-se minimizar o erro Tipo I. No nosso problema, isto acontece quando a taxa é maior que $9,28 \%$.

$3^{\circ}$ Cenário: Cin $=$ Cop. Neste cenário, a alta taxa de juros de $9,28 \%$ faz com que o custo de inadimplência seja igual ao custo de oportunidade. Sendo que a relação de 1 para 1 de cliente bom para cada cliente ruim faz a taxa de inadimplência aceitável se fixar em $50 \%$.

\section{Resultado do Modelo}

O modelo Logit foi utilizado através do programa Eviews 5. Para minimizar os problemas de heterocedasticidade, comum em dados de corte, utilizamos a matriz diagonal contendo os quadrados dos erros chamada de estimador de white.

Devidos aos problemas de colinearidade das variáveis econômico-financeiras e com o objetivo de sintetizar as informações contidas na matriz de dados, incorporando ao modelo um reduzido número de variáveis representativas e independentes, procedemos a análise fatorial dos componentes principais.

Fluxograma dos Resultados

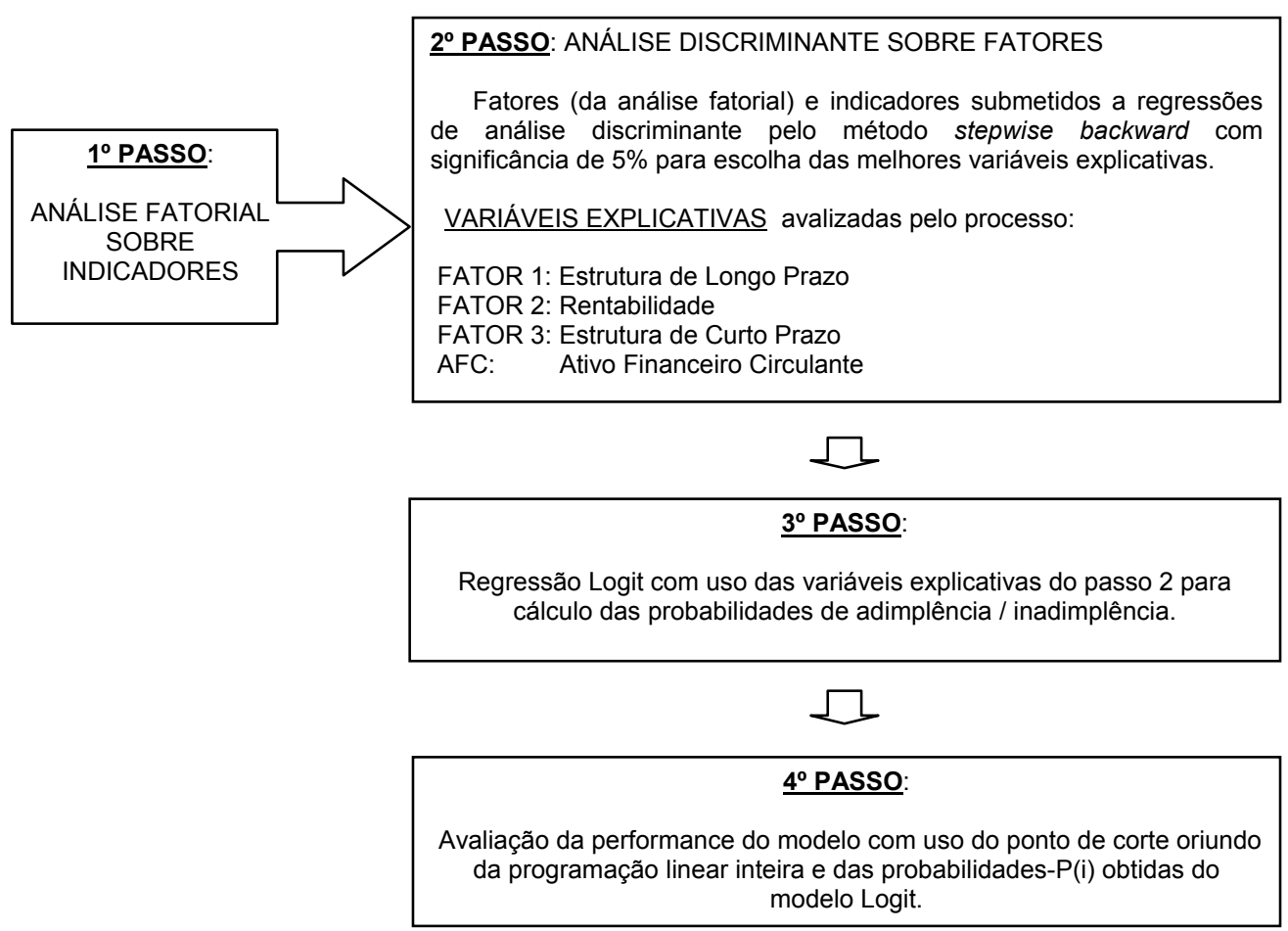

Pesquisa Operacional, v.28, n.2, p.263-284, Maio a Agosto de 2008 


\subsection{Resultados da Análise Fatorial}

Motivados pela alta colinearidade entre os indicadores econômico-financeiro, que pode causar problemas de inferência (previsão e testes de hipóteses), usamos a Análise Fatorial nos indicadores da Tabela 1, usando o Software SPSS 12.0.

Para verificar se os dados suportam uma análise fatorial, foram utilizados dois testes estatísticos. Um deles foi o de esferidade de Bartlett, e o outro o teste de Kaiser-Meyer-Olkin $(\mathrm{KMO})$, ambos os resultados foram favoráveis ao uso da análise fatorial. No primeiro, verificou-se a sua significância a $1 \%$ de probabilidade e o segundo, com valor de 0,61 , indicando a adequação da amostra.

Para definição dos fatores, usou-se o critério de se considerar apenas aqueles com auto-valor (variância total explicada pelo fator) maior que 1 e cargas fatoriais iguais ou superiores a 0,40 . Deste modo, os 4 primeiros fatores explicam $81,50 \%$ da variação de todas as variáveis utilizadas, sendo então bastante significativos.

Para a seleção dos indicadores que entraram como variáveis independentes do modelo, seguimos os seguintes passos:

i. Devido à multicolinearidade, procedemos a análise fatorial dos componentes principais, resultando em quatro fatores, F1, F2, F3 e F4;

ii. Verificação das variáveis que foram extraídas da análise fatorial conforme filtro realizado através do teste de Kaiser-Meyer-Olkin (KMO) e a observação da comunalidade de cada indicador;

iii. Através de análise discriminante, utilizamos o método stepwise backward com significância de 5\%. Por essa análise, é possível identificar-se quais variáveis independentes que mais explicam a classificação dos casos através da variável dependente, no caso, a Solvência/Insolvência. As variáveis que entraram no processo foram: Fatores F1, F2, F3 e F4, AFC, CT/PL, LC, ML, RentPL e AlaFin.

Estes quatro fatores juntamente com os seis indicadores foram incluídos na regressão stepwise como variáveis explicativas, cada fator representando um grupo de variáveis. Os três primeiros fatores juntamente com a variável Ativo Circulante Financeiro (ACF) se apresentaram significativos ao nível de $5 \%$ de significância, tendo sido então, incluídos como variável independente conforme Tabela 3 abaixo:

Tabela 3 - Denominação dos Fatores Utilizados.

FATOR UTILIZADO

Fator $1(\mathrm{~F} 1)$

Fator 2 (F2)

Fator 3 (F3)

$\mathrm{AFC}$
DEFINIÇÃO DO FATOR

Estrutura de Longo Prazo

(CTF, CT, ELP, DIVTL E LG)

Rentabilidade

(Fluxo BT e Rent AT)

Estrutura de Curto Prazo

(Composição e PFC)

Ativo Financeiro Circulante

Fonte: Resultado da Análise Fatorial sobre os dados. 
$\mathrm{O}$ indicador AFC revela a participação do capital financeiro no seu ativo, ou seja, revela os valores disponíveis na empresa para uso imediato, tal como caixa e bancos, aplicações financeiras, títulos e valores imobiliários, entre outros de curto prazo. Quanto maiores estes valores mais a empresa possui margem de segurança contra as adversidades do mercado. Assim, é de se esperar que o coeficiente deste indicador tenha sinal positivo, pois quanto maior AFC maior a probabilidade da empresa ser adimplente, de pagar seus compromissos financeiros.

O Fator F1 equivale a Estrutura de Longo Prazo, as dívidas que deverão ser liquidadas no longo prazo. Neste caso, quanto maior for F1, mais a empresa se aproxima da falta de liquidez, da insolvência financeira. Espera-se então que o coeficiente de F1 tenha sinal negativo. Do mesmo modo, o F3, como Estrutura de Curto Prazo, deverá ter o seu coeficiente com sinal negativo, pois quanto maior a dívida de curto prazo, mais a empresa terá a probabilidade de ser insolvente. Como as dívidas de curto são exigidas num prazo menor maior será a pressão sob a empresa para que produza recursos líquidos para fazer face a estes compromissos imediatos. Assim, espera-se que o coeficiente de F3 seja, em valor absoluto, maior que o F1.

O Fator 2 traduz a rentabilidade da empresa, assim, quanto maior os recursos gerados a partir da atividade da empresa, de sua operacionalidade, maiores as chances da empresa ter liquidez e consequentemente, manter-se solvente com seus compromissos. Deste modo, é de se esperar que F2 tenha seu coeficiente com sinal positivo, significando que quanto maior F2 maior será a probabilidade da empresa ser solvente.

\subsection{Resultados Econométricos do Modelo}

Para efeito da análise da performance dos modelos, utilizamos o ponto de corte de cada cenário resultante da Programação Linear Inteira. Por performance entenda-se a capacidade do modelo em discriminar empresas adimplentes e/ou inadimplentes fora da amostra. Quando o percentual de acerto leva em consideração ambos os grupos, defini-se como performance geral.

\subsubsection{Resultado do Modelo Logit}

Pode-se interpretar os resultados do modelo Logit a partir do quociente odds (equação 5). A interpretação dos coeficientes difere da análise discriminante. Como já citamos anteriormente, odds de um evento é definido como o quociente entre a probabilidade que o evento ocorra e seu complementar, onde " $e$ " elevado a potência $\beta_{k}$ é o fator no qual o odds muda quando a i-ésima variável independente aumenta em uma unidade. Os efeitos de cada variável do odds são observados tomando-se o antilog do coeficiente. Devido a exponencialidade dos coeficientes, quando o coeficiente é 1 leva a invariabilidade do odds, maior que 1 aumenta o odds e inferior a 1 diminui o odds. Se $\beta_{k}$ é negativo (positivo), o fator vai ser inferior (superior) a 1 , o que significa que o odds decresceu (cresceu).

Assim, o antilog do coeficiente negativo de F1 $(-0,638), 0,5283$, multiplica a chance em favor de adimplência em 0,5283 ou diminui a chance pelo fator 0,5283 . Também podemos dizer que a chance diminui em $47 \%$, resultado da fórmula $\left[\left(\mathrm{e}^{-0,638}-1\right) \times 100\right]$. Assim, as dívidas de curto prazo (F3) diminuem em torno de $52 \%$ a probabilidade em favor de adimplência quando F3 aumenta em 1 unidade. Como era esperado, um aumento de 1 unidade em F3, 
dívidas de curto prazo, terá um impacto maior que as dívidas de longo prazo representadas por F1.

As variáveis F2 (Rentabilidade) e AFC têm impactos positivos na chance em favor da adimplência.

$$
\frac{P_{i}}{1-P_{i}}=e^{b_{0}+b_{1} x_{i 1}+. .+b_{m} x_{i 2}}=e^{-0,57+9,22 A F C-0,638 F 1+0,486 F 2-0,738 F 3}
$$

Para espelhar a probabilidade de ocorrência de um evento, escrevemos a equação 16 a seguir.

$$
P_{i}=\frac{1}{1+e^{-Z i}}=\frac{1}{1+e^{-(-0,57+9,22 A F C-0,638 F 1+0,486 F 2-0,738 F 3)}}
$$

Os coeficientes mostraram-se significantes ao nível de 5\% de significância e os sinais foram compatíveis com a teoria. Observe que o valor absoluto de F3 é maior que o de F1, mostrando que é mais prejudicial dívidas de curto prazo. O Quadro 1 mostra os valores e significância dos coeficientes.

Quadro I - Resultados da regressão do Modelo Logit.

\begin{tabular}{crrrr} 
& \multicolumn{2}{c}{ Modelo Logit } & & \\
\cline { 2 - 4 } Variável & Coeficiente & Erro padrão & t-statistic & \multirow{2}{*}{ Value-p } \\
\hline \hline Constante & $-0,5704$ & 0,3277 & $-1,7403$ & 0,0818 \\
AFC & 9,22 & 2,942 & $+3,1341$ & 0,0017 \\
F1 & $-0,638$ & 0,2294 & $-2,7812$ & 0,0054 \\
F2 & 0,486 & 0,2416 & $+2,0111$ & 0,0443 \\
F3 & $-0,738$ & 0,2474 & $-2,9851$ & 0,0028 \\
\hline
\end{tabular}

Outra forma de interpretar o modelo Logit é calcular os efeitos marginais ou probabilidades marginais. Como já mostrado anteriormente, a probabilidade de ter a característica (no caso adimplente) varia $\rho(1-\rho) \beta_{i}$ em ralação a mudança marginal no valor de $X_{i}$. Usando-se o critério da chance proporcional conforme a fórmula $\eta=\vartheta^{2}+(1-\vartheta)^{2}$, encontramos $\eta=0,5055=50,55 \%$ e a probabilidade marginal (Pbmg) para cada variável relevante:

$$
\begin{aligned}
& \operatorname{Pbmg}(\mathrm{F} 1)=0,5055(1-0,5055) \times(-0,638)=-0,1595 \\
& \operatorname{Pbmg}(\mathrm{F} 2)=0,5055(1-0,5055) \times 0,486=0,1215 \\
& \operatorname{Pbmg}(\mathrm{F} 3)=0,5055(1-0,5055) \times(-0,738)=-0,1845 \\
& \operatorname{Pbmg}(\text { AFC })=0,5055(1-0,5055) \times 9,22=2,3050
\end{aligned}
$$

As probabilidades marginais acima significam o quanto irá variar a probabilidade para variações unitárias nas variáveis explicativas. Por exemplo: Um aumento de uma unidade na dívida de curto prazo ( $\mathrm{F} 3$ ), irá diminuir em $18,45 \%$ a probabilidade de adimplência da empresa. Já as dívidas de longo prazo (F1), a diminuição da probabilidade de adimplência é de $16 \%$. 
Neste momento faremos uso do Modelo de Decisão de Programação Linear Inteira para definir o Ponto de Corte $V c$ ideal para cada cenário. Utilizaremos os resultados do modelo Logit como base. Entenda-se por ideal o $V c$ ótimo encontrado na solução do sistema de minimização da função objetivo a qual é a soma dos custos de oportunidade e inadimplência. No quadro a seguir mostra-se o percentual de acerto na classificação correta das empresas. Assim, divide-se em Solvente, Insolvente e Geral. Em cada um deles, temos o percentual de classificação correta, por exemplo, para \% de acerto geral entenda-se o percentual de empresas que foram corretamente classificadas entre solventes e insolventes. Conforme já definido anteriormente, temos aqui três cenários cujos resultados encontram-se no Quadro 2.

$1^{\circ}$ Cenário: Cin $>$ Cop. Neste cenário, encontramos para o valor ótimo de equilíbrio no modelo de programação linear inteira, um ponto de corte $\mathrm{Vc}=0,79$. Este ponto de decisão produziu uma performance geral no nosso modelo de $45 \%$. No entanto, neste cenário o importante é minimizar o Erro Tipo II. Neste caso, o modelo teve a performance excelente de $91 \%$ de acerto para classificar os clientes insolventes.

Encontramos aqui um $V c$ alto de 0,79 , significando que o crédito só será aprovado para empresa cuja probabilidade de ser solvente seja superior a 79\%. O valor obtido é coerente e consistente, uma vez que instituições financeiras que praticam baixas taxas de juros não podem arriscar-se fazendo empréstimos a clientes com alto risco.

$2^{\circ}$ Cenário: Cin $<$ Cop. Neste cenário, a alta taxa de juros faz com que o custo de inadimplência seja menor que o custo de oportunidade. Aqui, o modelo de programação linear inteira encontrou, em sua solução ótima, um $\mathrm{Vc}=0,334$ com uma performance geral de $86 \%$. No caso, deve-se minimizar o Erro Tipo I, obtendo performance de $93 \%$ na classificação de clientes bons.

30 Cenário: Cin $=$ Cop. Neste cenário, a alta taxa de juros de $9,28 \%$ faz com que o custo de inadimplência seja igual ao custo de oportunidade. Sendo que a relação de 1 para 1 de cliente bom para cada cliente ruim faz a taxa de inadimplência aceitável se fixar em $50 \%$. Como era de se esperar, o ponto ótimo de corte, Vc ficou igual a 0,36 , próximo de 0,50 .

Quadro 2 - Modelo Logit - Resultados da Classificação por Cenários de Taxas de Juros x Custos.

\begin{tabular}{|c|c|}
\hline $\begin{array}{c}\text { Situação do } \\
\text { Cenário }\end{array}$ & $\begin{array}{c}\text { Taxa de } \\
\text { Juros }\end{array}$ \\
\hline
\end{tabular}

\% Acerto por Cenário Classificação

\begin{tabular}{|c|c|c|c|c|c|}
\hline Corte & & & Solvente & Insolvente & Geral \\
\hline 0,79 & $\mathrm{CIN}>\mathrm{COP}$ & $6 \%$ am & $31 \%$ & $91 \%$ & $45 \%$ \\
\hline 0,334 & $\mathrm{CIN}<\mathrm{COP}$ & $10 \%$ am & $93 \%$ & $61 \%$ & $86 \%$ \\
\hline 0,36 & $\mathrm{CIN}=\mathrm{COP}$ & $9,28 \%$ am & $89 \%$ & $70 \%$ & $85 \%$ \\
\hline
\end{tabular}




\section{Conclusão}

Um dos principais objetivos do artigo foi verificar se a Estrutura de Capital das empresas poderia servir como sinalizador para um modelo de risco de crédito da situação econômicofinanceira da empresa. Isto foi alcançado através das variáveis explicativas significativas estatisticamente utilizadas no modelo. Os fatores F1 e F3, Dívida de Longo Prazo e de Curto Prazo respectivamente mostraram que a estrutura de capital é um bom indicador da real situação da empresa.

Outro indicador relevante do lado da aplicação de capital, Ativo, foi o AFC, Ativo Financeiro Circulante, o qual se mostrou igualmente importante na determinação da insolvência empresarial.

Este estudo então mostrou que é possível, mesmo sob um ambiente de Informação Assimétrica, captar sinalizações das empresas para identificar com antecedência aquelas empresas mais propensas a se tornarem inadimplentes e aceitar ou negar crédito a luz destas probabilidades de insolvência. $\mathrm{O}$ critério de escolha deste ponto de corte se dá através de um modelo de decisão que incorpora os custos de oportunidade, inadimplência e a taxa de juros no contexto da política de crédito através do uso da Programação Linear Inteira.

Usamos o modelo Logit porque a análise discriminante requer a suposição de normalidade multivariada das variáveis independentes e matrizes de variância-covariância iguais nos dois grupos para que a regra de previsão seja ótima. Além disso, devido aos problemas econométricos já citados, a análise discriminante é meramente uma técnica de classificação, enquanto o modelo Logit analisa uma relação causal. Como não estamos interessados apenas numa classificação dicotômica das empresas, mas também na estimação dos coeficientes das variáveis independentes e, consequentemente, na determinação da probabilidade de ocorrência de insolvência, o modelo Logit é o mais apropriado ao nosso estudo.

A utilização da análise fatorial contribuiu para que pudéssemos usar toda informação disponível da empresa, mesmo aqueles indicadores com problemas de colinearidade. Diversos métodos estatísticos univariados e multivariados, assim como critérios qualitativos são usados na discriminação e classificação do risco. No entanto, o uso da Análise Fatorial qualificou ainda mais as variáveis independentes usadas, colocando-as em grupos de explicação que captam melhor os efeitos dos diversos indicadores econômico-financeiros. Neste ponto, ao delimitar as variáveis nos grupos de estrutura de capitais (dívidas de curto e longo prazos), fortalecemos um dos objetivos do trabalho que era averiguar o poder de explicação das variáveis ligadas à decisão da empresa em relação às suas fontes de financiamento e seu risco de crédito.

Uma das limitações deste trabalho é a não incorporação de algumas variáveis que, teoricamente, iriam contribuir na explicação do modelo, como variáveis de comportamento (caráter, cadastro, reciprocidade com o banco, etc.), variáveis de administração (decisões de projetos de curto e longo prazo da empresa, capacidade técnica da administração) e variáveis mercadológicas (produto $\mathrm{x}$ custo de insumos). No entanto, para o pesquisador externo, que é nosso caso, estas informações não estão disponíveis, mas poderiam contribuir conjuntamente com as variáveis aqui relacionadas. Outro ponto importante do modelo é a necessidade de revisão periódica. De fato, o modelo deve ser periodicamente alimentado com dados novos, à medida que se tornam disponíveis, pois os parâmetros aqui encontrados podem mudar com o curso do tempo devido aos novos "modus operandi" das empresas, novas tecnologias e ação da capacidade humana. 
Algumas contribuições deste trabalho podem ser elencadas:

i. A ratificação dos impactos dos endividamentos de curto e longo prazos sobre a probabilidade de inadimplência e como sinalizadores de estrutura de capital da situação financeira da empresa;

ii. Utilização das teorias sobre estrutura de capital para lastrear a indicação de variáveis explicativas e amenizar os efeitos da assimetria informacional;

iii. Utilização conjunta de técnicas de análise multivariada como a regressão Logit, Análise Fatorial e Programação Linear Inteira para construção de um modelo de decisão com a introdução de cenários que incluíram a taxa de juros e custos de oportunidade e inadimplência.

Este artigo não tem a presunção de esgotar o assunto de risco e decisão, mas ter contribuído para uma melhor compreensão das variáveis que determinam o risco de inadimplência com o objetivo de auxiliar a decisão de concessão de crédito.

\section{Referências Bibliográficas}

(1) Altmam, E.I. (1968). Financial ratios, discriminants analysis and the prediction of corporation bankruptcy. Journal of Finance, 23(4), 589-609.

(2) Altman, E.I. \& Baidya, T.K.N. \& Dias, L.M.R. (1979). Previsão de problemas financeiros em empresas. Revista de Administração de Empresas, 19(1), 17-18, jan./mar.

(3) Caouette, J.B. \& Altman, E.I. \& Narayanan, P. (1999). Gestão do risco de crédito: o próximo grande desafio financeiro. Qualitymark, Rio de Janeiro.

(4) Elizabetsky, R. (1976). Um modelo matemático para decisão de crédito no banco comercial. Dissertação de mestrado apresentado ao Departamento de Engenharia de Produção da Escola Politécnica da USP.

(5) Famá, R. \& Grava, J.W. (2000). Liquidez e a teoria dos elementos causadores de insolvência. Caderno de Pesquisa em Administração, USP, São Paulo, 1(12), 10-21.

(6) Famá, R. \& Grava, J.W. (2000). Teoria da estrutura de capitais - as discussões persistem. Caderno de Pesquisa em Administração, USP, São Paulo, 1(11), 27-36.

(7) Gehrlein, W.V. \& Wagner, B.J. (1997). A two-stage least cost credit scoring model. Annals of Operations Research, 74, 159-171.

(8) Gitman, L.J. (1997). Princípios de administração financeira. 3.ed., Harbra, São Paulo.

(9) Greene, W.H. (1997). Econometrics analysis. 3.ed., Prentice Hall.

(10) Haddad, P.R. (1989). Economia Regional - Teoria e métodos de análises. Banco do Nordeste do Brasil, Fortaleza.

(11) Jensen, M. \& Meckling, W.H. (1976). Theory of the Firm: managerial behavior, agency costs and ownership structure. Journal of Finance Economics, 3, 305-360.

(12) Johnston, J. \& Dinardo, J. (2201). Métodos econométricos. 4.ed., McGraw-Hill, São Paulo. 
(13) Markowitz, H. (1952). Portfolio selection. The Journal of Finance, p.89.

(14) Matias, A.B. (1978). Contribuições às técnicas de análise financeira: Um modelo de concessão de crédito. Dissertação de mestrado apresentado à faculdade de Economia da USP.

(15) Matarazzo, D.C. (1997). Análise financeira de balanços. 4.ed., Atlas, São Paulo.

(16) Modigliani, F. \& Miller, M.H. (1958). The cost of capital, corporate finance and the theory of investment. American Economic Review, 48, 201-297.

(17) Myers, S.C. (1990). Still searching for optimal capital structure. Journal of Applied Corporate Finance, 10, 185-194.

(18) Myers, S.C. (1988). New issues in corporate finance. European Economic Review, 32, 1.167-1.189.

(19) Rodrigues, W. Jr. \& Monteiro, G. (1999). Padrão de financiamento das empresas privadas no Brasil. Textos para Discussão $\mathrm{n}^{\circ}$ 653. IPEA.

(20) Ross, S. (1977). The determination of financial structure: the incentive approach The Bell Journal of Economics, 8, 23-40.

(21) Rummel, R.J. (1970). Applied factor Analysis. Northwestern University Press, Evanston.

(22) Salanié, B. (1998). The economics of contracts. Mit Press, Cambridge Massachusetts.

(23) Scarpel, R.A. \& Milioni, A.Z. (2002). Utilização conjunta de modelagem econométrica e otimização em decisões de concessão de crédito. Pesquisa Operacional, Rio de Janeiro, 22, 61-72.

(24) Scarpel, R.A. \& Milioni, A.Z. (2001). Aplicação de modelagem econométrica à análise financeira de empresas. RAUSP, 36, 80-88.

(25) Schilderinck, J.H. (1977). Regression and factor analysis applied in econometrics. Martinus Nejhaft Social Sciences Division, Lerdin.

(26) Silva, J.P. da, (1997). Gestão e análise de risco de crédito. Atlas, São Paulo.

(27) Wooldridge, J.M. (1997). Econometric analysis of cross section and panel data. The Mit Press, Cambridge. 